\title{
Moda, consumo e
} tendências: como a televisão e os influenciadores digitais instigam a moda no Brasil

Teresa Campos Viana Souza

Doutora, Centro Universitário de Belo Horizonte/ tecacviana@gmail.com

Orcid: 0000-0003-1841-2276 / lattes

Rita Ribeiro

Doutora, Universidade do Estado de Minas Gerais / rribeiroed@gmail.com Orcid: 0000-0003-0748-854X / lattes 


\title{
Moda, consumo e tendências: como a televisão e os influenciadores digitais instigam a moda no Brasil
}

\begin{abstract}
RESUMO
O presente artigo pretende discutir as relações entre a moda e a mídia e sua influência nas ações de consumo das pessoas. Tem como objetivo mostrar que as tendências de consumo são utilizadas pelas empresas para endossarem o processo de compra de algum produto. Tais tendências representam as inclinações dos consumidores e podem indicar as transformações vindouras no consumo dos produtos. A metodologia utilizada foi um estudo bibliográfico de como o desenvolvimento dos meios de comunicação, em particular a televisão, no Brasil e também uma análise de duas campanhas publicitárias com duas celebridades distintas a fim de entender como o endosso foi utilizado pela empresa. Foi percebido que utilizar celebridades ou influenciadores digitais é uma estratégia de marketing que se mostra eficaz quando se trata de apresentação ou venda de um produto, desde que tal celebridade apresente empatia e afinidade com o que é divulgado.
\end{abstract}

Palavras-chave: Moda. Consumo. Tendências 


\title{
Fashion, consumption and trends: how television and digital influencers instigate fashion in Brazil
}

\begin{abstract}
This article aims to discuss the relationship between fashion and the media and their influence on people's consumption actions. It aims to show that consumption trends are used by companies to endorse the process of buying a product. Such trends represent the inclinations of consumers and may indicate future changes in the consumption of products. The methodology used was a bibliographic study of how the development of the media, particularly television, in Brazil and also an analysis of two advertising campaigns with two different celebrities in order to understand how the endorsement was used by the company. It was realized that using celebrities or digital influencers is a marketing strategy that is effective when it comes to presenting or selling a product, as long as that celebrity has empathy and affinity with what is disclosed.
\end{abstract}

Keywords: Fashion. Consumption. Tendencies 


\title{
Moda, consumo y tendencias: cómo la televisión y los influencers digitales instigan la moda en Brasil
}

\begin{abstract}
RESUMEN
Este artículo tiene como objetivo discutir la relación entre la moda y los medios de comunicación y su influencia en las acciones de consumo de las personas. Su objetivo es mostrar que las empresas utilizan las tendencias de consumo para respaldar el proceso de compra de un producto. Estas tendencias representan las inclinaciones de los consumidores y pueden indicar cambios futuros en el consumo de productos. La metodología utilizada fue un estudio bibliográfico de cómo el desarrollo de los medios de comunicación, particularmente la televisión, en Brasil y también un análisis de dos campañas publicitarias con dos celebridades diferentes con el fin de comprender cómo fue utilizado el respaldo por parte de la empresa. Se percató que usar celebridades o influencers digitales es una estrategia de marketing que resulta efectiva a la hora de presentar o vender un producto, siempre $y$ cuando esa celebridad tenga empatía y afinidad con lo que se divulga.
\end{abstract}

Palabras clave: moda. consumo. tendencias 


\section{Introdução}

O presente artigo tem a intenção de demonstrar através de pesquisa bibliográfica e de análise de campanhas publicitárias, como a televisão e os influenciadores digitais têm um papel relevante no consumo da moda brasileira. Para tal, foram analisadas duas campanhas publicitárias encabeçadas por duas celebridades brasileiras. Uma delas, pode-se constatar,foi totalmente assertiva enquanto denota oserros na concepção da publicidade e a celebridade escolhida não endossou o produto da forma como a empresa esperava.

O século $X X$ foi marcado por grandes transformações no campo tecnológico e das comunicações. Essas mudanças trouxeram transformações na vida das pessoas no campo e nas cidades. Nos interessa saber se com o avanço dos meios de comunicação, os hábitos de consumo da população da cidades urbanas apresentaram mudanças.

A forma como as marcas dos produtos de moda e a mídia tratam as questões sociais são pontos relevantes para se pensar a moda. As pessoas querem consumir produtos de determinadas marcas, que supostamente pensam como elas, que têm os mesmos valores. Este é um fenômeno que, ainda que antigo, ganha proporções a partir da segunda metade do século $X X$.

Bourdieu (2017) nos traz o conceito de habitus que "são os princípios geradores de práticas distintas e distintivas", ou seja, são as formas de agir, pensar e ver o mundo das pessoas de acordo com a sua criação familiar. Para o autor, os sujeitos agiriam por uma estrutura incorporada, um habitus, que refletiria as características da realidade social no qual eles foram anteriormente socializados. A maneira de agir, pensar, de ver o mundo. A ação de cada sujeito tenderia assim a refletir e atualizar as marcas de sua posição social e as distinções estruturais que a definem. 
Bourdieu (2017) ainda afirma em sua teoria da boa vontade cultural que existe o esforço de apropriação da cultura dominante por parte daqueles que não a possuem, como exemplo podemos citar a aquisição de uma bolsa falsificada de uma marca famosa querendo assim demonstrar pertencimento a determinado grupo social. Existe também a contraposição: a hierarquia cultural dominante visando reverter a posição ocupada pela cultura dominada. Como exemplo podemos identificar o vestuário minimalista e "básico" por parte de um grupo abastado que não quer ser identificado pela ostentação.

Isso denota o caráter estratificador de classes sociais na moda. Ou seja, a burguesia copia o vestuário da nobreza, esta passa, então, a mudar seu vestuário com uma frequência cada vez maior, pois não pode usar os mesmos modelos que uma classe social inferior. Simmel (2008, p. 23), reforça a necessidade de imitação quando nos informa que esta "proporciona ao indivíduo o sossego de permanecer sozinho no seu agir."

O século XIX é conhecido como a época em que a moda teve mais progressos e o sentido do termo é consolidado. 0 avanço da indústria têxtil, a introdução da máquina de costura, o desenvolvimento do mercado de roupas prontas faz com que o acesso à moda seja facilitado, dando margem a uma certa democratização, o que não significa igualdade. Rainho (2002, p. 19) nos diz que "é no século XIX que tem origem uma produção diversificada de discursos sobre a moda. Nesse momento, ela se torna um objeto a ser mostrado, analisado e registrado."

Lipovetsky (2009, p. 79) acrescenta ainda que é a partir do século XIX e até a década de 1960 que a moda moderna passa a ser caracterizada por dois vieses: o da alta costura e o da confecção industrial. A confecção industrial faz com que 
a moda ganhe corpo e se apresente "sob signos de uma diferenciação marcada em matéria de técnicas, de preços, de renomes, de objetivos, de acordo com uma sociedade dividida em classes, com modos de vida e aspirações nitidamente contrastados."

Pode-se perceber que a moda é construída a partir de acontecimentos históricos que provocam variações no vestuário e na maneira de se vestir e se comportar em função desses mesmos acontecimentos. Os contextos políticos e sociais influenciam cada vez mais as tendências de moda e a própria história da moda. Roche (2007, p. 21) ainda reforça que a roupa passa a fazer parte de debates sobre o que é necessário e o que é supérfluo, o luxo e a mediocridade, riqueza e pobreza após os movimentos históricos da reforma e contra-reforma católica e protestante. O autor também deixa claro que "a história das roupas nos diz muito acerca das civilizações; ela revela seus códigos."

A moda foi e continua sendo um espelho da sociedade e também das manifestações sociais e culturais. Desde os tempos de guerra que os acontecimentos mundiais influenciam os hábitos de consumo e de moda da sociedade. Emily Durkheim ao definir fato social como as maneiras de se exercer no indivíduo uma coerção exterior que interfere em suas ações e atitudes e que é geral em dada sociedade indica que:

A maior parte de nossas ideias e de nossas tendências não é elaborada por nós, mas nos vem de fora, elas só podem penetrar em nós impondo-se, eis tudo o que significa nossa definição. Sabe-se aliás que nem toda coerção social exclui necessariamente a personalidade individual. (DURKHEIM, 2007, p. 4) 
Percebe-se, então que a moda está presente em nossas vidas, em nossas tomadas de decisões e na sociedade em que vivemos muito mais do que imaginamos.

\title{
2 A FORMAÇÃO DAS TENDÊNCIAS
}

Podemos definir tendência, primeiramente, a partir da etimologia da palavra. O termo deriva da palavra tendentia que vem do verbo tendere, do latim, que significa "tender para" ou ser "atraído por". Ou seja, desde os primórdios a palavra vem carregada do sentido de alteridade, originalidade. Dario Caldas, fundador da metodologia do escritório Observatório de Sinais ${ }^{1}$, que faz pesquisa e análise de tendências de comportamento e consumo desde 2002, aponta que:

\begin{abstract}
A etimologia relata, também, que a palavra permaneceu de uso raro até o século XVIII - o das Luzes, da Enciclopédia e da Revolução Francesa, não custa lembrar - quando foi retomada pela linguagem cientifica como "força dirigindo-se para um sentido determinado, tendendo para um fim" ou, simplesmente, "dinamismo", "força", "esforço", "impulso". É aqui, então, que o conceito de tendência adquire uma outra característica que o define até hoje: a sua finalidade, a ideia do movimento que se esgota em si mesmo. (CALDAS, 2013 p.89)
\end{abstract}

Podemos perceber que a vontade do ser humano em pesquisar o que estava por vir já existe há muitos anos. Caldas ainda completa que "o conceito de tendência que se generalizou na sociedade contemporânea foi construído com base nas ideias de movimento, mudança, representação do

${ }^{1}$ Observatório de Sinais é um escritório de inteligência estratégica e tendências.

http://observatoriodesinais.com.br/ 
futuro, evolução e sobre critérios quantitativos. (Caldas, 2013 p.57) $O$ estudo das tendências nos permite uma compreensão maior dos princípios e ideias que guiam e motivam a sociedade, elas são uma parte fundamental do nosso ambiente emocional, físico e psicológico.

Riezu (2011, p.31) entende como definição de tendência "um elemento que passeará pelo mercado - mais ou menos transformado - durante uns cinco anos". No mundo do coolhunting", existe também o termo fad "que tem um ciclo de vida muito mais curto, afeta um segmento muito pequeno de compradores e tem pouco potencial. Segundo a autora, outra forma interessante de diferenciar a tendência da fad é observar se o produto satisfaz uma necessidade. Para um produto permanecer no mercado, escolher a hora certa de lançar também é de extrema importância para que esse produto não se torne uma fad. A autora nos dá como o exemplo o caso do Ipod, a Apple esperou que as pessoas se familiarizassem com os reprodutores digitais de música para só assim lançar o produto. Outro fator importante são as possibilidades de acesso a tendência. Ela precisa ser "compreensível, barata, fácil de conseguir e atraente". E por último, a repetição do movimento, se existem manifestações similares em diferentes segmentos é sinal que a tendência se espalhou. Já as fads, a autora cita:

A fad vem tão rápido quanto se vai. Seus compradores, entusiastas, promovem o boca a boca, mas também são flutuantes. Hoje, eles gostam de uma coisa, amanhã de outra, e o mais importante não é "o que é", mas sim tê-la o quanto antes... Devido a essa volatilidade, as

${ }^{2}$ Coolhunting é um termo no mundo do marketing que se refere a previsão de futuras tendências e mudanças de consumo. 
fads são inimigas da análise, da implementação e do controle. Surgem espontaneamente e têm um ciclo de vida realmente curto: uma explosão repentina, um período hot e um ocaso abrupto. Costumam ter em comum uma característica mais divertida que útil. (RIEZU, 2011, p.33)

As transformações no mercado de consumo ocorridas no pós-guerra com a demarcação de novos públicos, aliada à crescente influência dos produtos midiáticos foi um fator de extrema importância para alavancar o estudo das tendências.

As tendências são utilizadas pelas empresas para endossarem o processo de compra de algum produto desejado. Elas representam as inclinações dos consumidores para um determinado sinal e são responsáveis por figurar as transformações vindouras da moda. As necessidades do ser humano são mutáveis, a vontade de pertencer a algo, de entender e ser entendido fazem parte da essência do homem. De acordo com Thompson:

Produtos mudam e modas têm suas ascensões e suas quedas. Porém a arquitetura da mente humana é antiga e as mais básicas necessidades do ser humano são eternas: as necessidades de pertencimento, de escape, de aspiração, de entender, de ser entendido. Esse é um dos motivos pelos quais as causas e consequências dos hits encontram paralelo na História e, como veremos, tanto os criadores como os públicos estão eternamente reprisando as ansiedades e as alegrias de culturas passadas. (THOMPSON, 2018, p. 15)

As tendências estão presentes em todas as áreas da sociedade, seja na moda de vestuário e acessórios, que serão endossados por celebridades, seja na política, no consumo, no lazer, na música e em diversas outras áreas. As pessoas estão sempre em busca do novo hit do momento.

Para Bauman (2013), o desejo de ser diferente e se destacar na multidão faz com que as pessoas procurem as últimas tendências de moda. 
Guiada pelo impulso de ser diferente, de escapar da multidão e da rotina competitiva, a busca em massa da última moda (do próprio momento) logo faz com que as atuais marcas de distinção se tornem comuns, vulgares e triviais; mesmo o menor lapso de atenção ou até uma redução momentânea da velocidade da prestidigitação podem produzir efeitos opostos aos pretendidos: a perda da individualidade. (BAUMAN, 2013, p. 25)

É preciso entender também que existem as micro, macro e megatendências. As microtendências são pequenas inovações que podem ser aplicadas em massa e muitas vezes se transformam em macrotendência quando se repetem com frequência. As macrotendências possuem uma duração maior e são o resultado de vários sentimentos da sociedade. Lindkvust (2010, p.6) ainda cita que as macrotendências podem durar "cerca de uma década ou duas e incluirão mudanças e ciclos econômicos, ventos políticos e surgimentos de novas tecnologias" Já as megatendências vão representar comportamentos maiores, em âmbitos globais e podem durar décadas. Geralmente são consequências de alguma mudança na economia, na política ou evoluções tecnológicas. Sobre as megatendências, Lindkvist, afirma: "estas são mudanças sociais profundas que costumam durar mais do que duas décadas." Podemos citar como exemplo, o grande avanço do conservadorismo pelo mundo. Muitos países, inclusive Brasil e Estados Unidos, elegeram como presidente da república, políticos da ala conservadora.

\section{DA TV AOS INFLUENCIADORES DIGITAIS}

Caldas (2013) aponta que o modelo trickle effect foi duramente criticado após a década de 60 pois foi constatado que algumas inovações não precisavam da legitimação da elite pois atingiam a classe média diretamente, como é o caso 
da moda lançada pelas novelas. Hoje em dia, a moda lançada pelos influenciadores digitais também não precisa da aprovação da elite, pois quem aprova são os próprios influenciadores.

O trickle effect foi criticado a partir dos anos 1960, quando a euforia consumista fez constatar que determinadas inovações atingiam diretamente as classes médias, sem precisar de legitimação das elites, isto é, sem originar-se, necessariamente, no topo da pirâmide; hoje, na mesma categoria, poderíamos citar as modas lançadas pelas novelas, que atingem diretamente vários estratos sociais. (CALDAS, 2013 p.351)

A mídia impressa figura entre os primeiros instrumentos de influência nos costumes da sociedade. No início do século $X X$, eram as revistas femininas que ditavam a moda e os costumes. As mulheres, para se tornarem exímias donas de casa, seguiam à risca tudo que esses veículos publicavam. Depois, com o surgimento do rádio, as notícias chegavam aos lares numa velocidade muito maior que anteriormente.

Antes, o cinema já se tornaria um veículo de mídia que influenciaria milhares de jovens pois tinha a capacidade de mobilizar um enorme número de espectadores em frente de uma tela gigante e colossal. O cinema foi e ainda é capaz de sugestionar modos de vestir, cortes de cabelos, formas de falar. Analisando ainda mais fundo a indústria cinematográfica, não são somente os filmes que irão afetar a sociedade de alguma forma, mas também os festivais e eventos de premiação da mídia como Oscar, Emmy, Festival de Cannes e outros. As celebridades que cruzam os tapetes vermelhos são alvos de prestígio e os telespectadores querem saber de onde são os vestidos, acessórios e quem fez as maquiagens. Sendo assim, Freitas (2005) ainda nos informa 
da importância da mídia como articuladores das tendências de moda.

\begin{abstract}
A mídia é um dos maiores articuladores das tendências da moda, não só por meio da publicidade e propaganda, mas também pelas coberturas jornalísticas de grandes eventos esportivos e artísticos. As telas do cinema, da televisão, dos computadores e dos outdoors luminosos têm um papel preponderante nesse contexto. Hoje, a moda é, sobretudo, consumo, seja de objetos, seja de ideias. A partir desse ponto de vista, não podemos considerar só os aspectos comerciais, mas todos os aparatos ideológicos que são produzidos ou apropriados pelos meios de comunicação de massa. (FREITAS, 2005, p.126)
\end{abstract}

Assim, como artefatos criados pelo design o figurino dos personagens de filmes, séries e novelas carrega as características que, também, influenciarão na identificação dos espectadores com o personagem. O figurino, segundo Castro e Costa (2010), é o traje ou conjunto de acessórios e indumentária que será utilizado pelo artista para compor seu personagem. O figurino dos personagens do cinema e da televisão têm uma importância muito grande, pois, além de compor o personagem, marcar a mudança de personalidade de um personagem, marcar uma mudança de tempo e época, determinar o caráter do personagem, ele pode também marcar uma época, virar referência de moda e, consequentemente, aparecer nas vitrines das lojas e se tornar objeto de desejo e consumo dos milhares de espectadores.

Assim como hoje, o público queria imitar seus ídolos e, para isso, vestia-se de forma parecida, senão igual a eles. Como foi mencionado anteriormente, a moda sempre foi o espelho das grandes movimentações da sociedade, o cinema, na década de 1930 e durante todo o século XX, a televisão no meio do século XX e podemos dizer que também os blogs, nos dias de hoje, são as grandes vitrines dessas transformações. 
Em um sentido bastante geral do figurino, sendo parte integrante da direção de arte, é criar o visual da narrativa televisiva através das vestimentas de suas personagens. Assim o figurinista vai desenvolver e/ou escolher roupas que entendam as necessidades do roteiro e da direção, respeitando o conceito geral do que quer passar o autor e o diretor da história. 0 figurino não pode ser visto destacado de um contexto maior. Funciona como uma importante fonte auxiliar para se entender a narrativa, e muitas vezes desempenha papel de destaque devido a sua importância para a visão que se tem do que se pretende realizar com o programa de ficção televisivo. (CUNHA, 2009, p. 32)

Lipovetsky (2009) nos mostra que a cultura de massa está inserida na moda desde a década de 50, quando as estrelas e ídolos contribuíram para a recuperação da indústria.

Se a cultura de massa está imersa na moda é também porque gravita em torno de figuras de charme com sucesso prodigioso, que impulsionam adorações e paixonites extremas: estrelas e ídolos. Desde os 1910-20, o cinema jamais deixou de fabricar estrelas, são elas que os cartazes publicitários exibem, são elas que atraem o público para as salas escuras, foram elas que permitiram recuperar a enfraquecida indústria do cinema nos anos 1950. Com as estrelas, a moda brilha com todo o seu esplendor, a sedução está no ápice de sua magia. (LIPOVETSKY, 2009, p. 248)

Nesse contexto, as celebridades se tornam importantes atores nesse processo de endosso. Se um ator ou atriz de renome passa a divulgar determinado produto, a chance de esse produto ter sucesso nas vendas é muito maior do que sem endosso algum, conforme cita McCraken (2012):

O processo de endosso depende das propriedades simbólicas da celebridade endossadora. [...] A celebridade endossadora é definida como qualquer indivíduo que aproveita o reconhecimento público e que usa esse reconhecimento em nome de um bem de 
consumo ao aparecer com ele num anúncio. (MCCRAKEN, 2012, p.109)

Lipovetsky (2009) ainda reforça que a idolatria pelas estrelas, por mais contraditório que possa parecer, revela uma individualidade em relação ao seu meio familiar e social. E que esse fenômeno se manifesta mais os entre jovens é "porque nessa idade os gostos e as preferências estéticas são os meios principais de afirmação da personalidade". (LIPOVETSKY, 2009, p. 255)

Quando a televisão, chega aos lares mundiais, a influência que a mídia faz sobre a vida das pessoas já é grande, mas se transformaria em algo muito maior. No Brasil, a televisão de 1950 até 1964 ainda era considerado um artigo de luxo, poucas casas possuíam. Muitas vezes, juntava-se toda a vizinhança para assistir aos programas de auditório ou as novelas. A televisão chega e já se torna um importante veículo de comunicação e influência de consumo para as massas. Williams (2016) ainda nos elucida com a importância do surgimento da tecnologia para a televisão e como seu surgimento foi decisivo para os novos sistemas de comunicação que viriam depois

A televisão ainda nos dias de hoje é uma das mídias que mais influencia o consumo das pessoas, pois ela é uma vitrine do que acontece no mundo. Segundo Thompson (2018), a primeira vez que os americanos passaram mais tempo interagindo com dispositivos digitais do que assistindo televisão foi em 2012.

\footnotetext{
A televisão substituiu o filme como a mídia mais popular de contação de histórias visuais, junto com uma imensa mudança na atenção e nos dólares, passando do ingresso para cinema uma vez por semana às contas de TV a cabo, cujos pagamentos mensais suportaram um vasto ecossistema de esportes ao vivo, dramas tanto brilhantes quanto formulaicos, assim como
} 
infinitos reality shows. (THOMPSON, 2018, p. 20)

Partindo desse pensamento, podemos afirmar que a televisão é um canal importante para a disseminação de tendências e também sua fixação. Como as pessoas passam boa parte da vida assistindo a programas desta mídia, elas estão sujeitas à influência desse veículo de informação.

Com o surgimento da internet, as informações são transmitidas cada vez mais rápido e com mais frequência. Junto com a internet surgem novos modelos de comunicação como os blogs e as redes sociais. No início dos anos 2000, os blogs tinham uma popularidade muito grande na rede pois eram os meios mais rápidos de se obter informação, no caso específico da moda, as blogueiras se tornaram as novas referências de tendências tomando o lugar das editoras de estilo das revistas de moda.

Essas pessoas se tornaram um fenômeno de vendas de produtos, influenciando diretamente uma grande parte de consumidoras que seguiam suas indicações. Acredita-se que esse fenômeno se deu por elas estarem mais perto da massa e assim o público passa a ter mais acesso aos produtos, conforme a blogueira e atualmente influenciadora digital Camila Coutinho cita em seu livro:

Diferentemente de uma revista, que já nasce com um público bem definido, o blog e as redes sociais têm a liberdade encantadora de simplesmente serem o que quem escreve quiser. A audiência encontra o blog e fica do seu lado por isso, pelos interesses parecidos, como num grupo de amigos. O mundo começou a valorizar cada vez mais opiniões pessoais. Produtos indicados por meninas comuns somem das prateleiras. O fenômeno atraiu o interesse da imprensa tradicional, que reconheceu e validou a força desses novos formadores de opinião. Ao mesmo tempo, os veículos começaram a sentir no bolso o incômodo de ver parte da verba publicitária, antes garantida, 
sendo direcionada para garotas que escreviam dos seus quartos. Rolou um período de resistência e polêmicas, mas foi uma mudança de comportamento sem volta. (COUTINHO, 2018, p. 23)

Além dos blogs, as redes sociais como Facebook, Instagram, YouTube, Twitter colocaram essas blogueiras cada vez mais perto do seu público pois elas estão exatamente onde seus seguidores também estão, na academia, no shopping, no salão de beleza e em outros lugares. Hoje, as blogueiras do início dos anos 2000 deram lugar aos chamados influenciadores digitais. Segundo, Silva (2016, p.5) o termo influenciadores digitais se refere:

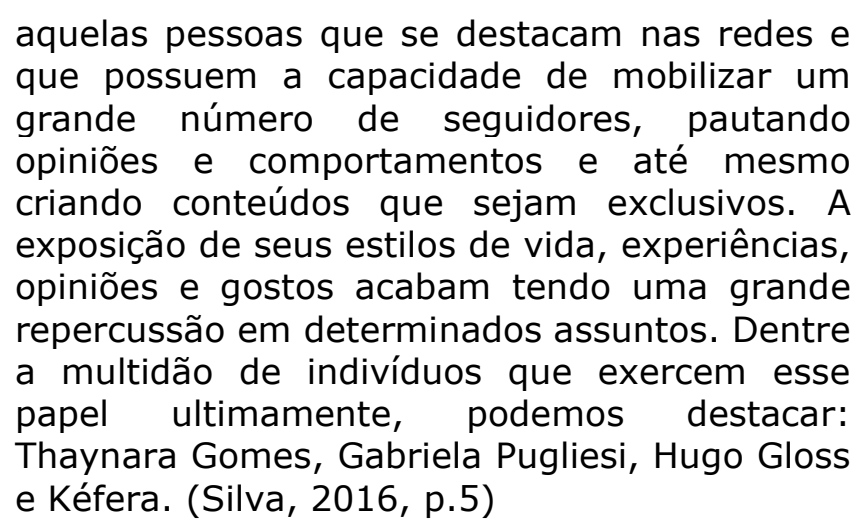

A televisão e a internet fazem também com que as pessoas tenham uma proximidade maior com as celebridades. Elas deixam de ser aqueles seres inatingíveis do cinema e passam a frequentar os lares das pessoas todos os dias. E por terem acesso a milhões de pessoas, dada a amplitude de acesso promovida pela internet e pela televisão, conseguem se tornar agentes endossadores de produtos e ideias. A forma como é endossado um produto costuma ser a garantia de sucesso de venda. Não basta somente a celebridade aparecer usando ou divulgando um produto; os consumidores, hoje, sabem se aquele endosso é verdadeiro ou algo que foi construído 
apenas para fazer com que eles consumam o produto, de acordo com McCraken:

A eficiência do endossador depende, em parte,
dos significados que ele ou ela trazem para o
processo de endosso. O número e variedade de
significados contidos nas celebridades é muito
grande. Distinções de tipo de status, classe,
gênero, idade, personalidade e estilo de vida são
representados no conjunto de celebridades
disponíveis, colocando uma paleta de
significados extraordinariamente variada e sutil
à disposição do sistema de MKT. (MCCRAKEN,
2012 p.114)

A escolha da celebridade determinará o sucesso de vendas de um produto ou de uma ideia. Tomemos como exemplo a escolha da cantora Sandy para endossar a cerveja Devassa. Pode-se dizer que o que o endosso dessa figura pública não foi válido; a empresa não conseguiu atingir o consumidor através dessa campanha, talvez porque a celebridade em questão já havia anunciado, por diversas vezes, que não gosta de cerveja, conforme é informado pelo site Economia.ig ${ }^{3}$. Ou a empresa não se preocupou em levar ao consumidor uma imagem verdadeira, apostando que a cantora, apenas pelo fato de ser famosa, garantiria o sucesso do produto, ou pretendeu surpreender positivamente o consumidor com a inusitada garota-propaganda, quem sabe insinuando que pode sempre haver uma "devassa" onde não se espera, essa seria uma outra hipótese levantada pelo site vermelho.org ${ }^{4}$. Seja como for, a estratégia não funcionou e os consumidores, por não identificarem Sandy com a marca, não compraram a ideia e a campanha não foi o sucesso esperado.

\footnotetext{
${ }^{3}$ https://economia.ig.com.br/empresas/comercioservicos/piadas-sobre-a-sandy-e-devassa-seespalham-no-twitter/n1238131968605.html

${ }^{4}$ http://www.vermelho.org.br/noticia/148980-1
} 
FIGURA 1: PROPAGANDA DEVASSA

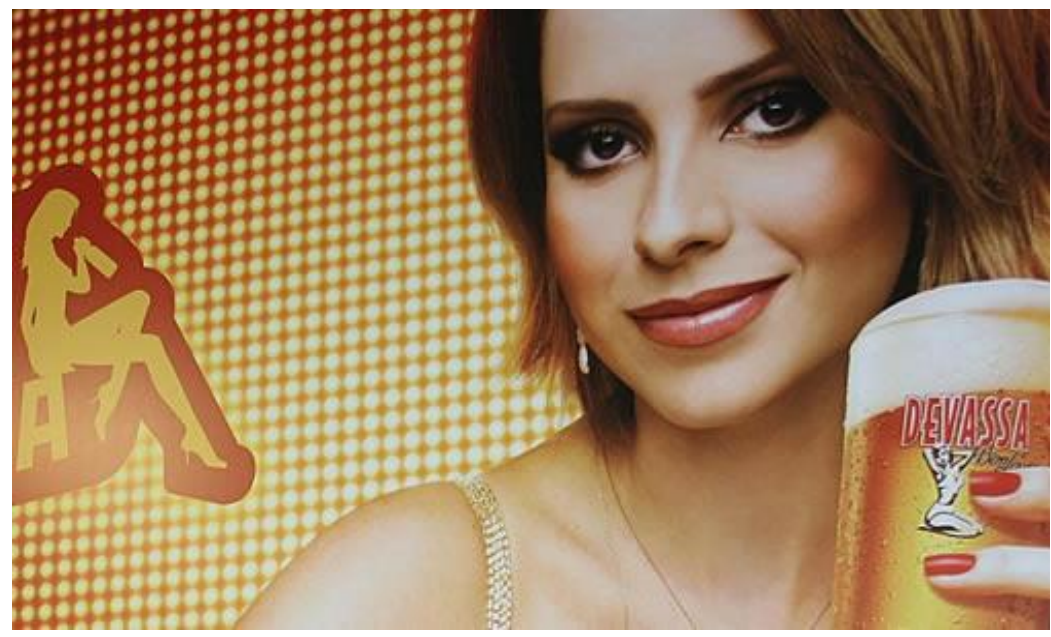

Fonte: http://tyrannusmelancholicus.blogspot.com.br/2011/05/associar-marcasprodutoscelebridades.html Acessado em: 27/03/2018

A moda mudou muito ao longo dos últimos 150 anos, para Crane (2008), é importante diferenciar entre moda de classe e moda de consumo, esses dois tipos incorporam três aspectos da moda: significado, difusão e diferenciação social. Para esse estudo, focaremos na moda de consumo, que ainda segundo a autora "há muito mais diversidade estilística e muito menos consenso sobre o que está "na moda" em determinado período. Ainda citando Crane a moda de consumo, "é criada para satisfazer supostas exigências de diversas categorias de consumidores, principalmente jovens, que a usam como meio de definir e expressar sua identidade pessoal."

Já no próximo exemplo, a celebridade endossadora consegue mostrar ao consumidor que o produto faz realmente parte da sua vida. Na figura 2, o ex-jogador de tênis Gustavo Kuerten é o garoto propaganda da marca de roupas Lacoste. Neste caso, o endosso é perfeito, pois essa marca foi criada por um jogador de tênis e ainda é a patrocinadora de grandes jogadores da atualidade, como Novak Djokovic e Alize Cornet. 
O endosso aqui se torna claro e válido. O consumidor não se sente enganado e consegue enxergar as possibilidades da compra.

FIGURA 2: GUGA E LACOSTE

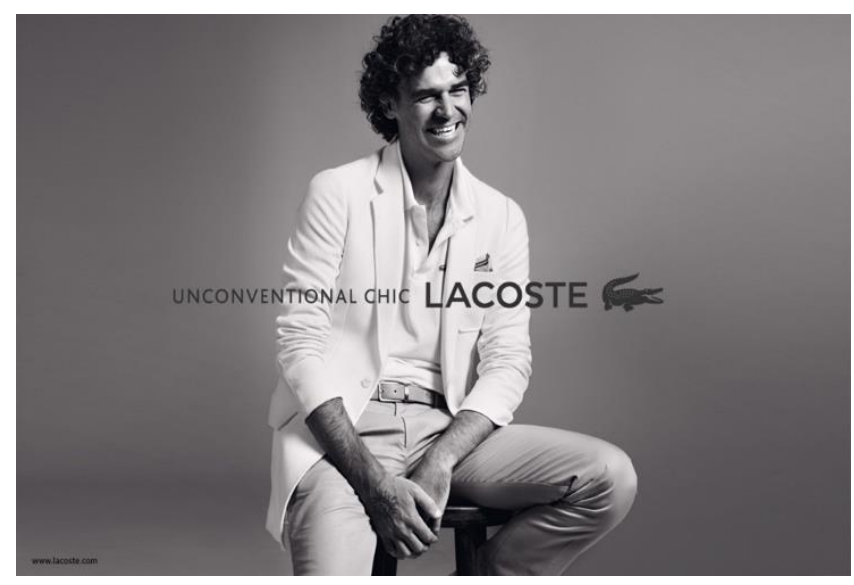

Fonte: http://br.fashionnetwork.com/news/Gustavo-Kuerten-e-o-novo-rosto-da-campanha-LacosteUnconventional-Chic-,257511.html\#.WrqvyIUfIFU Acessado em: 27/03/2018

McCraken (2012), nos informa da importância do endosso perfeito:

São precisamente os significados da celebridade que a tornam útil para o processo de endosso. Um endosso é bem-sucedido quando molda-se uma associação entre os significados do mundo cultural de um lado e do produto endossado do outro. (MCCRAKEN, 2012 p.115)

A população se interessa pelo mundo das celebridades porque faz parte do cotidiano, e a publicidade usa esses significados culturais para divulgar produtos e promover tendências de moda, maquiagem, penteados e hábitos, conforme afirma Lipovetsky (2009, p. 248):

As estrelas despertaram comportamentos miméticos em massa, imitou-se amplamente sua maquiagem dos olhos e dos lábios, suas mímicas e posturas; houve até, no decorrer dos anos 1930, concursos de sósias de Marlene Dietrich e de Greta Garbo. Mais tarde, os penteados, "rabo de cavalo" ou ondulados de Brigitte Bardot, as aparências descontraídas de 
James Dean ou Marlon Brando foram modelos em evidência. (LIPOVETSKY, 2009, p. 248)

A questão é como o consumidor enxerga esses instrumentos de transferência. Segundo McCraken (2012), o consumidor percebe as pessoas, objetos e contexto do anúncio que estão contidos nos produtos $e$, se forem bem trabalhados, o processo de transferência é quase que imediato. Hinerasky (2014, p.7) corrobora dizendo que:

O reconhecimento das marcas em torno do potencial das personalidades levou à recorrente busca por parcerias ou contratação desses operadores individuais na divulgação publicitária, parte das estratégias e da compreensão do mercado contemporâneo. (Hinerasky, 2014, p.7)

Vale, ainda, falar do uso das T-shirts como painéis de divulgação de ideias, como a luta mundial contra o câncer de mama, as camisetas do programa de proteção às tartarugas do projeto TAMAR, as camisetas dos Médicos sem Fronteiras etc.

Os influenciadores digitais do século XXI se tornaram capazes de influenciar um nicho de mercado e são capazes de mudar estratégias de investimento em publicidade porque conseguem atuar na preferência de consumo de uma nova geração de consumidores e público.

\section{CONSIDERAÇÕES FINAIS}

Conforme podemos perceber, as mudanças que ocorreram em todos os âmbitos da sociedade no final do século XIX e início do século XX trouxeram transformações na forma como se consumia. Cada país se desenvolveu de forma diferente, com base em suas condições sociais, econômicas e culturais. 
Com isso, houve uma grande migração da população do campo para a cidade e uma mudança significativa nas necessidades de consumo da população da época.

Durante o século $X X$, a comunicação teve uma grande influência nos hábitos de consumo dos habitantes das cidades. Com a chegada e a democratização da televisão e da internet, as pessoas passaram a ter mais acesso ao que chamamos de tendências de moda. As atrizes da televisão passam a ser modelo de atitude e estilo de vida pois estão frequentemente em nossas casas e os influenciadores digitais passaram a fazer parte da nossa vida, temos a sensação que eles falam diretamente conosco, com isso o endosso de um produto e a legitimação de um estilo de vida passa a ser mais real do que antes era passado pelas atrizes do cinema e do rádio e também nas passarelas de desfiles de moda.

Foi possível perceber que a utilização de celebridades e influenciadores digitais é assertiva e eficaz quando se trata de apresentar e vender um produto ao público.

Percebe-se ainda que a mídia além de ajudar na influência de consumo de diversos produtos, também consegue disseminar, com uma velocidade mais rápida, ideias e estilos de vida. As pessoas se sentem mais confiantes em aderir a alguma tendência quando percebem que outras também estão usando e quando essas pessoas são as atrizes das novelas ou as influenciadoras digitais, o endosso ao produto é muito mais eficiente e rápido. A mídia consegue colocar em pauta assuntos, ideias, movimentos e tendências de moda numa velocidade e num alcance muito grande.

\section{REFERÊNCIAS}

BAUMAN, Zygmunt. A cultura no mundo líquido moderno. Rio de Janeiro: Zahar, 2013.

BOURDIEU, Pierre. Razões Práticas: sobre teoria da ação. Campinas: Papirus, 2017 
CALDAS, Dario. Observatório de sinais: teoria e prática da pesquisa de tendências. São Paulo, Observatório de Sinais, 2013.

CASTRO, M; COSTA, N. Figurino - o traje de cena, Iara - Revista de Moda, Cultura e Arte, São Paulo, v. 3, n. 1, 2010.

COUTINHO, Camila. Estúpida, eu?: a blogueira que conquistou seu lugar no mundo da moda. Rio de Janeiro: Intrínseca, 2018.

CRANE, Diane. Reflexões sobre a moda: o vestuário como fenômeno social. In: Cultura e consumo: estilos de vida na contemporaneidade/ Maria Lucia Bueno, Luiz Octávio de Lima Camargo. Organizadores. - São Paulo: Editora SENAC São Paulo, 2008.

CUNHA, V. M. A moda na mídia: a telenovela como expoente. Uma análise de Viver a vida. 2009. Monografia (Bacharelado em Comunicação Social) - Universidade Federal do Rio Grande do Sul, 2009. Disponível em <http://hdl.handle.net/10183/32945>. Acesso em: 10 mai. 2018.

DURKHEIM, Émile. As Regras do Método Sociológico. 3. ed. São Paulo: Martins Fonte, 2007. Tradução de Paulo Neves.

FREITAS, Ricardo F. Comunicação, consumo e moda: entre os roteiros das aparências. In: Comunicação, mídia e consumo/Escola Superior de Propaganda e Marketing. v.2, n.4 (julho 2005) - São Paulo: ESPM, 2005.

HINERASKY, Daniela Aline. O Instagram como plataforma de Negócio de Moda: dos "it-bloggers" às "it-marcas". In: CONGRESSO INTERNACIONAL DE COMUNICAÇÃO E CONSUMO (COMUNICON), 8 a 10 out. 2014. Anais... 2014. ISBN:978-85-99790-21-2. Disponível em: http://www.espm.br/download/Anais_Comunicon_2014/links/GT0 6.html

LIPOVETSKY, Gilles. O império do efêmero: a moda e seu destino nas sociedades modernas. São Paulo: Companhia das Letras, 2009.

LINDKVIST, Magnus. O guia do caçador de tendências: como identificar as forças invisíveis que moldam os negócios, a sociedade e a vida. São Paulo: Editora Gente, 2010.

MCCRAKEN, Grant. Cultura \& Consumo II. Rio de Janeiro: Mauad, 2012.

RAINHO, Maria do Carmo Teixeira. A cidade e a moda: novas pretensões, novas distinções - Rio de Janeiro, século XIX. Brasília: Editora Universidade de Brasília, 2002. 172 p.

ROCHE, Daniel. A cultura das aparências: uma história da indumentária (séculos XVII - XVIII). São Paulo: Editora Senac São Paulo, 2007.

RIEZU, Marta Domínguez. Cool Hunters: caçadores de tendências na moda. Tradução de, Paulo Augusto Almeida Seemann. São Paulo: Editora Senac São Paulo, 2011.

SIMMEL, G. Filosofia da moda e outros escritos. Lisboa: Edições Texto e Grafia, 2008. 
SILVA, C.R.M; TESSAROLO, F.M. Influenciadores Digitais e as Redes Sociais Enquanto Plataformas de Mídia. In: Intercom - Sociedade Brasileira de Estudos Interdisciplinares da Comunicação. São Paulo, 05 a 09/09/ 2016

THOMPSON, Derek. Hit makers: como nascem as tendências. Rio de Janeiro: Harper Collins, 2018. 368 p. 